\title{
The Purpose, Tasks, Provisions of A Person- Centered Intensive Program Psychotherapy
}

\author{
Mariam Vachagan Mehrabyan \\ $\mathrm{PhD}$ in Psychology NA NASRA lecturer, The head of the Psychological centre "Zhesture",
}

\begin{abstract}
Person-centered intensive program psychotherapy is the systematic application of modern psychotherapeutic approaches, where it is important the approach to client's psychological complaint in intensity and coordination. There are already defined terms for solving psychological problems and several specialists can work with the problem. The stage of psychodiagnosis is important, where collaboration with the psychiatrist may be necessary. From identification the common patterns and the statistical analysis of the cases from 2009-2019 at the Psychological Center "Zhesture", it becomes clear that a large number of psychological problems in the modern world require an intensive program approach. Within the framework of Person-centered intensive program psychotherapy, there are deadlines for solving the problem, for example, 36 meetings for neurotic symptoms, 42 hours work with anxiety attacks /during more intensive visits/. Family psychotherapy lasts 24 meetings; by the way, the first 8 meetings with couples are implemented individually, 24 meetings for various fears in the case of child psychotherapy, 8 meetings with parents. 36 months are appointed for the children with autism spectrum disorder: meetings are held twice a week with 4 specialists and every 6 months we are organizing a discussion with the team and family. In the provisions of Personcentered intensive program psychotherapy it is important to highlight the teamwork of professionals with the techniques from different areas, such as cognitive, Jungian, psychoanalytical, gestalt.
\end{abstract}

Key words: Person-centered, intensive, program, psychotherapy 


\section{Social science, Humanities \& Education}

15 - 17 December, 2020
Berlin,Germany

\section{Introduction}

In the modern world, a person is regularly subjected to stress (distress, eustress), which, due to the speed of the century, causes fatigue, high anxiety, depression, apathy and other mental conditions. From 2009-2019 Psychological Center "Zhesture" has been collecting customer preliminary data, analyzing individual cases, identifying common patterns, discussing new techniques, developing a new methodological approach.

\section{Theoretical methodological basis}

The idea of Person-centered intensive program psychotherapy arose as a result of the techniques used during many practical psychotherapeutic works, the discussions of the specialists who used these techniques, and the supervision.

As it is already a pure truth that in case of different psychological problems different psychological areas are preferred ${ }^{1}$, and since psychological problems are often unclear, there is a need for the involvement of several specialists. Previously after completing the work there have been attempts to guide to another specialist or to apply the eclectic approach, when one specialist has used psychotherapeutic techniques of several areas, but our experience (2009-2019) has shown that the simultaneous involvement of specialists from different as well as related fields is much more effective than the classical approach. There is a demand for intensive program psychotherapy, where in many cases the client is perplexed, resisted, and distrustful about the long-term work in a number of classical psychotherapeutic areas.

The term "person-centered" differs substantially from the "client-centered" Rogerian term. Based on the client's resource-centered, psychotherapeutic, effective and useful techniques for personal growth, we have noticed the following patterns during the stages of our work:

An individual, a citizen, a person at any stage of socialization, with the relevant knowledge, abilities, skills, motivation, value system, personal resources, applies to a psychologist. Our work plan is as follows:

First stage: a telephone call, primary complaint

Second stage: visit, acquaintance, psycho-diagnosis

Third Stage: consultation on complaints and psychodiagnostic results

The fourth stage: psychotherapy.

Often with his own resources, the person does not go from the third stage, which is consultation to a fourth stage that is psychotherapy. It means he does not

\footnotetext{
${ }^{1}$ Cognitive psychotherapy for emotional, anxiety disorders, Jungian approach to traumas, gestalt for life scenarios, psychoanalysis for childhood problems, positive for psychosomatic manifestations and so on.
} 


\section{Social science, Humanities \& Education}

15 - 17 December, 2020

Berlin,Germany

become a "client". However, many cases (30\%) are resolved during the consultation stage.

In the fourth stage, teamwork is based on a combination of several areas.

Figure 1. Structure of Person-centered intensive program psychotherapy before psychotherapy

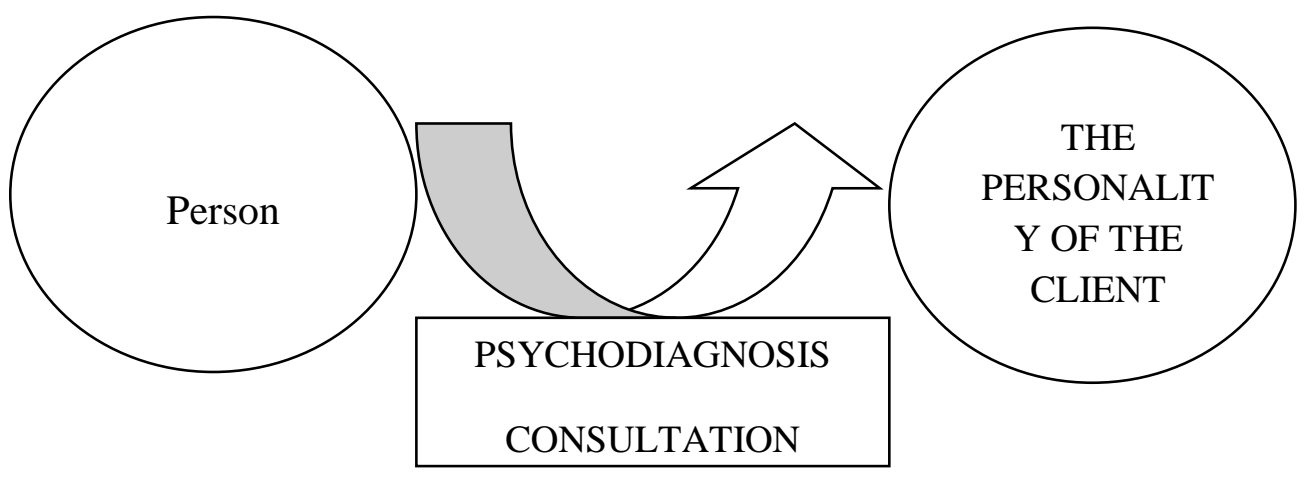

The term "intensive" 2 is found in Fromm-Reichmann (1951) intensive psychotherapy, based on Freud's psychoanalytic and Sullivan's interpersonal psychotherapy (1953). Intensive psychotherapy during its many years of experience is known for its positive results in the clinic of neuroses as well as psychoses. It also works with the "client" who has emotional, psychosomatic, neurotic, psychotic manifestations.

In intensive psychotherapy, the psychotherapist achieves their goals in working with the client through insights, by the way of realizing the unconscious causes of psychological phenomena. The symptom is eliminated; the social life of the person is restored. The dynamics of the development of the client's problem is an important part of the process. Unlike other psychotherapeutic areas, intensive psychotherapy differs in principle from the formulation of the problem, which is also one of the principles of Person-centered intensive psychotherapy. That is, to formulate the problem in the context of its origin, dynamics and interpersonal relationships, to assess the degree of mental health of a person by:

- Realization of obvious interpersonal relationships

- How well a person controls their behavior in interpersonal relationships

- Reporting on internal psychological and emotional feelings;

- Identify their tendencies, inclinations, dreams,

- Analyze and generalize own experience.

${ }^{2}$ The term "intensive" used by us is based on the non-harm principle and from the point of view of theoretical methodological analysis means an intensive approach to a person's psychological problem. Intensive - fast, not hasty, accurate, concrete, clear approach to solving a person's psychological problem. 


\section{Social science, Humanities \& Education}

In this way psychotherapy is viewed as an interpersonal interaction between the psychotherapist and the client. Such interpersonal interaction is not only procedural but also contextual when the client internalizes the information and the psychotherapist participates-observes.

Intensive psychotherapy works effectively with a psychiatrist when:

- Forgotten feelings become actual

- Investigation of fears, dangers associated with forgotten emotional experiences

- Resistance analysis

- Creating an atmosphere of safety and trust when the therapist listens very attentively and interprets their memories, actual relationships.

A very important principle in this theory is the respect for the client based on the view that the client's difficulties are not very different from the therapist's difficulties. This statement by Fromm-Reichmann is closely connected to his humanistic orientation, scientific convictions, based on psychiatric facts. ${ }^{3}$

The term "program" within the Person-centered intensive psychotherapy comprises an individual Program to the person's psychological problem (Provision 11), consisting of unique person-centered intensive techniques capable of solving a number of psychological problems.

Within the framework of Person-centered intensive program psychotherapy, all categorized problems have their deadlines of solution, for example, 36 meetings for neurotic symptoms, 42 hours work with anxiety attacks /during more intensive visits/. Family psychotherapy lasts 24 meetings; by the way, the first 8 meetings with couples are implemented individually, 24 meetings for various fears in the case of child psychotherapy, 8 meetings with parents. 36 months are appointed for the children with autism spectrum disorder: meetings are held twice a week with 4 specialists and every 6 month we are organizing a discussion with the team and family.

After summarizing the results of the psychodiagnosis, the relevant specialist begins work on a pre-determined therapeutic program (Person-centered intensive program psychotherapy, provision 6).

The theoretical basis for a person-centered intensive program psychotherapy are following Rogerian factors

${ }^{3}$ B.D. Karvasarskij, Jenciklopedija psihoterapii, SPB, 2000 
$4^{\text {th }}$ International Conference on

\section{Social science, Humanities \& Education}

15 - 17 December, 2020

Berlin,Germany

1. Therapist-Client Psychological Contact: This first condition simply states that a relationship between therapist and client must exist in order for the client to achieve positive personal change. The following five factors are characteristics of the therapist-client relationship, and they may vary by degree.

2. Client Incongruence or Vulnerability: A discrepancy between the client's self-image and actual experience leaves him or her vulnerable to fears and anxieties. The client is often unaware of the incongruence.

3. Therapist Congruence or Genuineness: The therapist should be self-aware, genuine, and congruent. This does not imply that the therapist be a picture of perfection, but that he or she be true to him- or herself within the therapeutic relationship.

4. Therapist Unconditional Positive Regard (UPR): The clients' experiences, positive or negative, should be accepted by the therapist without any conditions or judgment. In this way, the client can share experiences without fear of being judged.

5. Therapist Empathy: The therapist demonstrates empathic understanding of the clients' experiences and recognizes emotional experiences without getting emotionally involved.

6. Client Perception: To some degree, the client perceives the therapist's unconditional positive regard and empathic understanding. This is communicated through the words and behaviors of the therapist.

As to the deadlines, the basis for solving different problems have been A. Beck's cognitive psychotherapy approaches ${ }^{4}$

The work from 2009-2019 is carried out by representatives of different psychological areas (psychologists, psychotherapists). In the psychological center

"Zhesture" according to the provisions of Person-centered psychotherapy ${ }^{5}$ the work starts from Call center. The psychologist-specialist answers the calls with the

\footnotetext{
${ }^{4}$ Therapy generally consists of 15-25 sessions at weekly intervals. The moderately to severely depressed patients usually require interviews on a twice-weekly basis for at least 4-5 weeks and then weekly for 10-15 weeks. We generally taper the frequency to once every 2 weeks for the last few visits and recommend "Booster therapy" after the completion of the regular course of treatment. These
} follow-up visits may be scheduled on a regular basis or may be left to the discretion of the patient. We have found that the average patient returns to three or four "booster" visits during the year following termination of formal therapy/Aaron Beck, A Rush, B. Shaw, G. Emery, Cognitive therapy of depression, New York, 1979, p.6/

${ }^{5}$ Person-centered intensive programmed psychotherapy 
1. Person-centered intensive program psychotherapy sees the essence of the person prior to becoming a visitor, emphasizing the strengths of the Armenian human character in the context of contemporary crosscultural theories, and the possibilities for their usage

2. Psychological Problems in Person-Centered Intensive Program Psychotherapy are classified based on the data of the sociological research of the archive of 2007-2020/ Appendix 1 / of the Psychological Center "Zhesture"

3. In a person-centered intensive program psychotherapy, each psychological problem is described and defined according to international standards. The term of psychotherapeutic work is set for each person (Appendix 2).

4. A work plan is drawn up and a professional team is selected for each person in person-centered intensive programmed psychotherapy.

5. Person-centered intensive program psychotherapy proceeds in a phased manner.

6. The first stage of person-centered intensive program psychotherapy begins with psycho-diagnosis by a specially designed package (Appendix 3).

7. The second stage of person-centered intensive program psychotherapy is the discussion of the results of psycho-diagnosis with the person-centered intensive program psychotherapist.

8. The results, professional team, term and amount are discussed in the Professional Council of person-centered intensive program psychotherapy.

9. Each novelty is summarized and presented in the form of a scientific article after discussing the results of psycho-diagnostics. The goal is to develop and create an optimal package of psychodiagnostics for primary but in-depth analysis of the problem, which will make person-centered intensive program psychotherapist more tailored to society's needs.

10. The third stage of person-centered intensive program psychotherapy is the beginning of the therapeutic work.

11. Person-centered intensive program psychotherapy is flexible in the individual development of psychotherapy program of each problem.

12. Person-centered intensive program psychotherapy is planned for all people without age limitation, religious and gender discrimination.

13. Person-centered intensive program psychotherapy is interdisciplinary and involves collaboration with specialists of different fields (psychiatry, neurology, sexopathology, pediatrics), which is attached in written form to the individual card of the person.

14. The applicability and effectiveness of working techniques of Person-centered intensive program psychotherapy are evaluated on the basis of individual feedback, and are discussed at the Professional Council of Person-centered intensive program psychotherapy every three months. 
$4^{\text {th }}$ International Conference on

\section{Social science, Humanities \& Education}

15 - 17 December, 2020

Berlin,Germany

following scheme: name, surname, age, what is bothering you, and appoints relevant specialist. The first visit is not a therapeutic, but a psycho-diagnostic (Lüscher, Leonhard, Projective Methods, Beck Depression Scale, Jung, Sheehan Anxiety Rating Scale (ShARS)). The methodological apparatus is based on a complaint registered at the Call Center. The team of psychologists includes representatives of cognitive, gestalt, neurolinguistic programming, Jungian, psychoanalytic, psychodrama, Rogerian, positive areas.

During abovementioned years, the psychotherapeutic work, the process, the description of each visit, the techniques used are described in our localized personal data card. The Personal data card is the following:

* The information below is protected by law and is not subject to disclosure PERSONAL DATA CARD/for adults/r

Name, middle name and last name

Age $\operatorname{Sex}$

Passport data

Marital status

Psychologist

Address

Phone: Cell: TellE-mail:

The date of diagnostics /examination/ of the problem-

The date of discussion of the results of psycho-diagnosis

\section{PROBLEMS}

\section{Table 1}

\begin{tabular}{|c|c|c|c|c|c|c|}
\hline $\begin{array}{c}\text { Family } \\
\text { problems }\end{array}$ & Sticky thoughts & Insomnia & Low mood & \\
\hline $\begin{array}{c}\text { Personal } \\
\text { problems }\end{array}$ & & Depression & & Suspiciousness & Aggression & \\
\hline $\begin{array}{c}\text { Health } \\
\text { problems }\end{array}$ & Tension & Emotion & Fatigue & \\
\hline $\begin{array}{c}\text { Communication } \\
\text { problems }\end{array}$ & Addiction & & Lack of motivation & Absent mindedness & \\
\hline Anxiety & Jealousy & & Stress & Betrayal & \\
\hline Fears & $\begin{array}{c}\text { Low self- } \\
\text { esteem }\end{array}$ & Feeling of loneliness & Divorce & \\
\hline
\end{tabular}

15. A person-centered intensive program psychotherapeutic course annually summarizes its research, novelty in the form of scientific articles, reports, participation in international conferences, video recording, group roundtable discussions. 
$4^{\text {th }}$ International Conference on

Social science, Humanities \& Education

15 - 17 December, 2020

Berlin,Germany

Other problems

Brief Description of the Problem:

How did you find out about our center?

Have you visited a neurologist?

Have you received any medication?

Has any specialist worked with your problem or have you tried to overcome it yourself? If yes, how?

Has there been any person with psychological / mental problems in your family?

The note of the specialist of psycho-diagnostics

The appointed date

Number of weekly visits

Amount

Instructions of the specialists

* The information below is protected by law and is not subject to disclosure

\section{PERSONAL DATA /for kids/}

Name, middle name and last name of the parent

Name, middle name, last name and age

Date of birth

Sex

Psychologist

Passport data of the parent

Marital status of the parent

Address

Phone: Cell:

Tell

E-mail:

The date of diagnostics /examination/ of the problem

The date of discussion of the results of psycho-diagnosis 
$4^{\text {th }}$ International Conference on

Social science, Humanities \& Education

15 - 17 December, 2020

Berlin,Germany

\section{PROBLEMS}

Table 2

\begin{tabular}{|c|c|c|c|}
\hline $\begin{array}{l}\text { Communication } \\
\text { problems }\end{array}$ & $\begin{array}{l}\text { Nocturnal } \\
\text { enuresis }\end{array}$ & Stubbornness & Sound problems \\
\hline Fears & Emotion & Falsehood & Hyperactivity \\
\hline Depression & Stress & Autism & Complexes \\
\hline Addiction & $\begin{array}{c}\text { Lack of } \\
\text { motivation }\end{array}$ & $\begin{array}{c}\text { Developmental } \\
\text { problem }\end{array}$ & Low mood \\
\hline Low self-esteem & Aggression & Stuttering & $\begin{array}{c}\text { Concentrating } \\
\text { difficulty }\end{array}$ \\
\hline Insomnia & $\begin{array}{c}\text { Absent } \\
\text { mindedness }\end{array}$ & Speech delay & $\begin{array}{l}\text { Sticky thoughts } \\
\text { and actions }\end{array}$ \\
\hline
\end{tabular}

Other problems

Brief Description of the Problem:

How did you find out about our center?

Have you visited a neurologist?

Have you received any medication?

Has any specialist worked with your problem or have you tried to overcome it yourself? If yes, how?

Has there been any person with psychological / mental problems in your family?

Which pregnancy has it been?

How did the pregnancy go?

What diseases did the child get?

What traumas did the child have?

What institutions has the child attended / attends and for how long?

Are there disagreements with family members regarding child education?

Genetic diseases

The note of the specialist of psycho-diagnostics

The appointed date

Number of weekly visits 
$4^{\text {th }}$ International Conference on

Social science, Humanities \& Education

15 - 17 December, 2020

Berlin,Germany

Amount

Instructions of the specialists

Complaint

Date: the end of therapeutic visits. Notes-

Other problems found during therapeutic visits

Work done to overcome the existing problems

The first therapeutic visit

The total number of visits , attended

Pause for therapeutic visits

Amount paid

The end of therapeutic visits

Amount paid

The first therapeutic visit: Date:

The second therapeutic visit: Date:

The third therapeutic visit: Date:

The fourth therapeutic visit: Date:

The fifth therapeutic visit: Date:

The sixth therapeutic visit: Date:

The seventh therapeutic visit: Date:

The eighth therapeutic visit: Date:

The end of therapeutic visits. Notes

Feedback 
$4^{\text {th }}$ International Conference on

\section{Social science, Humanities \& Education}

15 - 17 December, 2020

Berlin,Germany

There are points in the Personal Data Card where the psychotherapist writes separately about insights, changes in the therapeutic plan, and the last point in the Personal Data Card is the feedback to the specialist.

This eclectic, coordinated approach which we have developed we have called PersonCentered Intensive Program Psychotherapy. After every 8 visits, the client writes a summary. The psychological problems listed in the presented statistics were written by people on their first visit to the relevant section of the personal Card.

Figure 2: Summarized data of the statistics

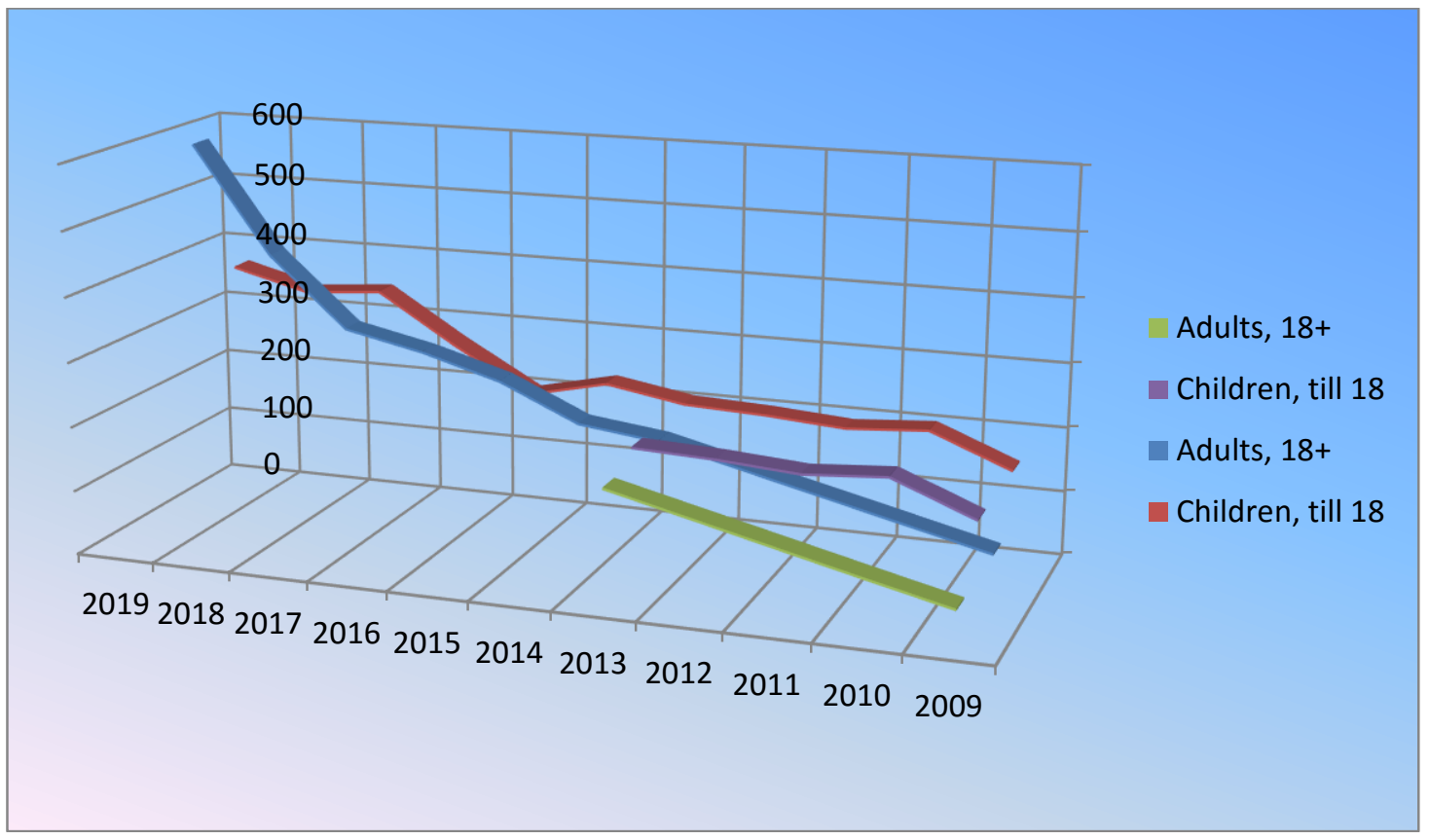

Below is a list of the psychological problems we have been working on since 2009 .

Table 3. List of psychological problems identified for adults in 2009-2019/n=950/

\begin{tabular}{|c|c|c|c|c|c|}
\hline $\begin{array}{c}\text { Family } \\
\text { problems }\end{array}$ & Sticky thoughts & Insomnia & Low mood & \\
\hline $\begin{array}{c}\text { Personal } \\
\text { problems }\end{array}$ & Depression & Suspiciousness & Aggression & \\
\hline $\begin{array}{c}\text { Health } \\
\text { problems }\end{array}$ & Tension & Emotionality & Fatigue & \\
\hline $\begin{array}{c}\text { Communication } \\
\text { problems }\end{array}$ & Addiction & Lack of motivation & Absent mindedness & Betrayal & \\
\hline Anxiety & Jealousy & Stress & Divorce & \\
\hline Fears & $\begin{array}{c}\text { Low self- } \\
\text { esteem }\end{array}$ & Feeling of loneliness & & & \\
\hline
\end{tabular}


$4^{\text {th }}$ International Conference on

\section{Social science, Humanities \& Education}

15 - 17 December, 2020

Berlin,Germany

Table 4. List of child Psychological Problems Complemented by Statistics at

Psychological Center "Zhesture" in 2009-2019/n=950/

\begin{tabular}{|c|c|c|c|}
\hline $\begin{array}{c}\text { Communication } \\
\text { problems }\end{array}$ & $\begin{array}{l}\text { Nocturnal } \\
\text { enuresis }\end{array}$ & Stubbornness & Sound problems \\
\hline Fears & Emotionality & Falsehood & Hyperactivity \\
\hline Depression & Stress & Autism & Complexes \\
\hline Addiction & $\begin{array}{c}\text { Lack of } \\
\text { motivation }\end{array}$ & $\begin{array}{c}\text { Developmental } \\
\text { problem }\end{array}$ & Low mood \\
\hline $\begin{array}{l}\text { Low self- } \\
\text { esteem }\end{array}$ & Aggression & Stuttering & $\begin{array}{c}\text { Concentrating } \\
\text { difficulty }\end{array}$ \\
\hline Insomnia & $\begin{array}{c}\text { Absent } \\
\text { mindedness }\end{array}$ & Speech delay & $\begin{array}{c}\text { Sticky thoughts } \\
\text { and actions }\end{array}$ \\
\hline
\end{tabular}

The statistics clearly shows this pattern: $n=950,534$ of which are women and 413 are men. Throughout the year, the center has been visited by 21 couples (30-50 years old), 364 clients under 18 and 586 adults. For both adults and children, "fear" as a problem comes first.

n586=n 128 Fears

n364= n101 Fears

Next in line are "anxiety" complaints - 67, "I am tensed" - 64, "I am depressed" - 45, "sticky thoughts" - 40. Children have such a dynamic. Aggression - $\mathrm{n}=100$, communication problem $-\mathrm{n}=41$, stubborn $-\mathrm{n}=32$. By the way, children's problems are mentioned by parents, which is confirmed or denied as a result of psychodiagnosis. In the context of widespread information (psychological articles, films, TV programs) over the past 10 years, statistics have changed not only the types of applicants but also the types of problems.

Table 5

\begin{tabular}{|l|l|l|l|l|l|l|l|l|l|l|}
\hline $\mathrm{n}=210$ & $\mathrm{n}=290$ & $\mathrm{n}=311$ & $\mathrm{n}=350$ & $\mathrm{n}=385$ & $\mathrm{n}=421$ & $\mathrm{n}=448$ & $\mathrm{n}=552$ & $\mathrm{n}=654$ & $\mathrm{n}=752$ & $\mathrm{n}=950$ \\
\hline $\mathrm{nA}=60$ & $\mathrm{nA}=90$ & $\mathrm{nA}=12$ & $\mathrm{nA}=15$ & $\mathrm{nA}=18$ & $\mathrm{nA}=19$ & $\mathrm{nA}=25$ & $\mathrm{nA}=28$ & $\mathrm{nA}=31$ & $\mathrm{nA}=419$ & $\mathrm{nA}=58$ \\
& & 0 & 0 & 5 & 0 & 5 & 1 & \\
\hline $\mathrm{nCh}=15$ & $\mathrm{nCh}=20$ & $\mathrm{nCh}=19$ & $\mathrm{nCh}=20$ & $\mathrm{nCh}=20$ & $\mathrm{nCh}=22$ & $\mathrm{nCh}=19$ & $\mathrm{nCh}=26$ & $\mathrm{nCh}=34$ & $\mathrm{nCh}=333$ & $\mathrm{nCh}=36$ \\
0 & 0 & 1 & 0 & 5 & 6 & 8 & 7 & 3 & & 4 \\
\hline 2009 & 2010 & 2011 & 2012 & 2013 & 2014 & 2015 & 2016 & 2017 & 2018 & 2019 \\
\hline
\end{tabular}


$4^{\text {th }}$ International Conference on

\section{Social science, Humanities \& Education}

15 - 17 December, 2020

Berlin,Germany

According to the psychological problems

Table 6

\begin{tabular}{|c|c|c|c|c|c|c|c|c|c|c|c|}
\hline Adults & 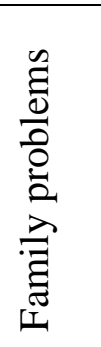 & $\begin{array}{l}\bar{\Xi} \\
\overline{0} \\
\overline{0} \\
0 \\
0 \\
0 \\
0\end{array}$ & 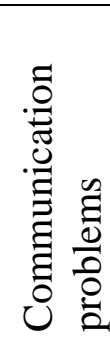 & 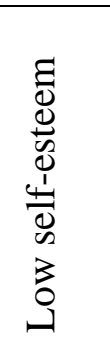 & 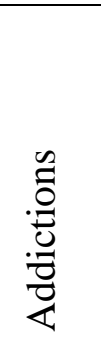 & 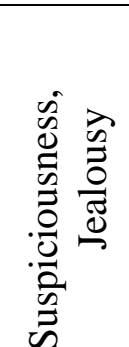 & 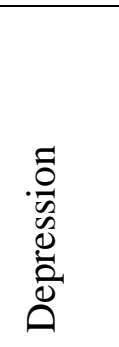 & 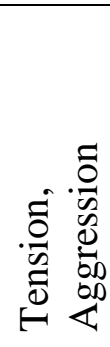 & 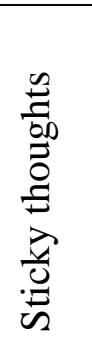 & 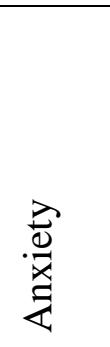 & 营 \\
\hline Children & 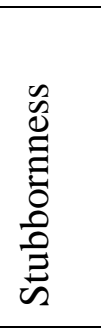 & 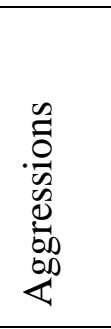 & 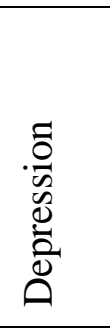 & $\begin{array}{l}\overrightarrow{8} \\
8 \\
\frac{0}{0} \\
\frac{0}{\pi} \\
\text { II }\end{array}$ & 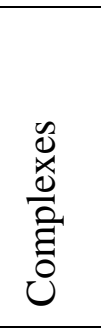 & 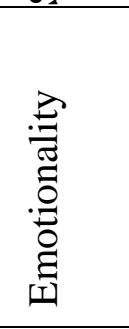 & 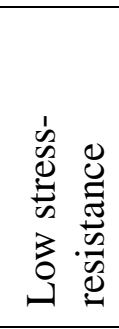 & 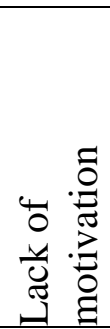 & 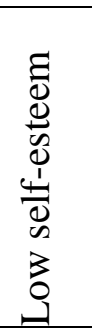 & 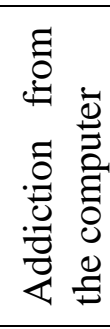 & 营 \\
\hline $\begin{array}{l}\text { According } \\
\text { to the dates }\end{array}$ & 2009 & 2010 & 2011 & 2012 & 2013 & 2014 & 2015 & 2016 & 2017 & 2018 & 2019 \\
\hline
\end{tabular}

\section{The presentation of the case}

It is also important to address the therapeutic process in the context of intensive programmed psychotherapy. Here is one case from family psychotherapy involving spouses, then children. The family is 15 years old, have two sons, live in Yerevan city in their apartment.

They visited to the psychological center "Zhesture" in June 2019 by the following complaint:

Husband- The client is quite tensed, has severe headaches. He mentions that he has been restless for a long time, lost his father at an early age, created everything from nothing, but his suspicion and tension do not calm him down, he doesn't feel better from anything. Two years ago he gained hepatitis $\mathrm{C}$ from the hospital after operating glands, now he has been cured, but neurosis deepened. He is aggressive, anxious, restless. He used afobazole and non-stress (the wife mentioned it).

Wife- She had one miscarriage after getting married. The first child was born three years later and now they have two children. Her husband is jealous and suspicious, has not let her work. His father died a year ago, after that his condition worsened. He uses non-stress and afobazole. She is more worried about her husband's condition.

The family psycho-diagnostic package, which includes the "Draw Your Family, Wiesbaden questionnaire", showed that their compatibility is high, but the husband is 


\section{Social science, Humanities \& Education}

overtensed, and the wife has psychosomatic problems. Intensive Program Psychotherapy-Family Psychotherapy /M. Bowen/ neuromuscular reflexotherapy, was appointed for 6 months-twice a week. During the course, a genogram was performed, which revealed that husband has deep psychological traumas and complexes associated with losing his father at an early age.

After four visits to the correction of gender-role problems, the woman's psychosomatic problems (headache, weakness in the limbs) have been also resolved.

Subsequently, the couple reported a problem with the elder boy. The boy / 13 years old / has been examined with Teenage Package / Projective Methods, Lüscher /. The result of the psycho-diagnosis showed that the child had a behavioral problem (is getting excited, is being aggressive, also beats his brother).

The child went to the child psychologist for 4 visits, and the parents started working with a parenting specialist within intensive program psychotherapy, and we had not stopped the neuromuscular reflexotherapy. By the way, they overcame family psychotherapy in two months instead of 6 months. The boy had a behavioral identification with his father, and since his father was calm, overcoming his complexes, they gained effective communication in the family as a result of parenting.

The mentioned case is also the best intensive and effective one which was overcome through the intensive program psychotherapy. In the 21 st Century, when we do not have time, we are involved in gadgets, do not communicate with relatives, our school of psychology offers Person-Centered Intensive Program Psychotherapy.

\section{Conclusion}

Summarizing 10 years of experience, analyzing well-known theorists, therapeutic areas, well-known techniques, we have presented a new theoretical conceptualization that includes specific, intensive and psychotherapeutic techniques for the plan of each case. Especially in the case of anxiety attacks, the intensity of visits and anxiety reducing techniques have great importance for resolving the problem. In our program, any neurotic symptom, a psychosomatic manifestation, requires an individual approach, an analysis of the causality of the problem, realizing the cause, a dialogue with the body. Solving family problems within a person-centered intensive psychotherapy program concludes with the drawing clear personal areas, developing a team and collaborative family scenario. Experience has shown that the deadlines developed by our approach always needs to be reduced, that is to say, sniper work reduces the recurrence of symptoms. 
$4^{\text {th }}$ International Conference on

\section{Social science, Humanities \& Education}

15 - 17 December, 2020

Berlin,Germany

\section{References}

1. Aaron Beck (1979), A Rush, B. Shaw, G. Emery, Cognitive therapy of depression, New York, 425p

2. Karl Leonhard(1976), Akzentuierte Persönlichkeiten, Hardcover, 328 p.

3. Max Lüscher (1972), „The Lüscher Colour Test", Remarkable Test That Reveals Your Personality Through Color, Pan Books, 180 p.

4. Beck, A.T., Ward, C. H., Mendelson, M., Mock, J., \& Erbaugh, J. (1961) An inventory for measuring depression. Archives of General Psychiatry, 4, 561-571.

5. B.D. Karvasarskij(2000), Jenciklopedija psihoterapii, SPB,

6. https://psychology-tools.com/test/zung-depression-scale

7. http://www.zhest.am/test/pay/6 